versity of Aix-Marseille. It describes in detail optical instruments and devices used in spectroscopy, ranging from the prism spectrometer to apparatus for Fourier transform methods, and is the first book, as far as I know, which covers the whole field. In the translation opportunity has been taken to add a short account of recent developments in the use of interferograms as diffraction gratings.

A short, introductory chapter is used to establish the significance of terms such as radiance, resolving power and luminosity, and these together with the conception of instrumental profile are then used extensively in subsequent chapters in the relative evaluation of different instruments and techniques. This is a very unconvincing chapter, possibly because the author avoids the use of units, but fortunately it is not an indication of the level of the remainder of the book.

The design, properties and limitations of prism and grating spectrographs are thoroughly discussed, and a chapter is devoted to the production and properties of gratings, including a brief account of the Merton-NPL process. In the latter the description of the preparation of a usable grating from a helical ruling is misleading: the pellicle removed from the cylinder is not itself mounted on glass and used as a mould (like a Thorp replica), but its pattern is impressed into the surface of a gelatine coated blank. In the early days of the process this gelatine grating after hardening was the final product, but later more durable gratings were made in Marco resin using the gelatine "master" as a mould. Contrary to the opinion expressed, in the spectral region for which they are intended these replica gratings compared favourably with the products of the interferometrically controlled flatbed ruling engine, and still do. A short account is also given of the preparation and properties of "holographic" gratings: is the use of this term (elsewhere, as well as in this book) really justified? The idea of using interferograms as diffraction gratings goes back at least as far as Rayleigh, and their actual use at least as far as Burch! The big step forward has been due to the advent of the laser as a powerful, coherent source and to the use of photo-resist materials for recording the interference patterns.

Prism and grating spectrometers and monochromators are described in detail, and their properties discussed and compared with those of spectrographs; here the term instrumental profile is defined and its significance indicated. The principle of the grill spectrometer is described, and its advantage of increased étendue is outlined. The remaining third of the book is concerned with interference spectroscopy, commencing with a lengthy account of the
Fabry-Perot étalon spectrometer. A few pages are devoted to the Sisam interferometer of Connes, and finally there is an account of the use of the Michelson interferometer in Fourier transform spectroscopy.

In content the translation differs only a little (as indicated above) from the French original; the latter has a much more pleasing format and typeform, but the diagrams in the translation are greatly improved-they appear to have been generally re-drawn-and the few plates are vastly superior (it is a pity, however, that their connexion with the relevant text could not have been made more obvious).

The translation has been excellent; the book appears to have been virtually re-written in English, which is as it should be. I can really find only two points of contention. The first is perhaps trivial: for "objective de chambre" why use "focusing lens" instead of "camera lens"? The second is of importance, because the English title is misleading: 1his book is concerned with the instruments used in spectroscopy, and not with the subject of spectroscopy itself and the French title makes this clear. Of course, spectroscopists will find it exceedingly useful; one can always get the best out of instruments with a knowledge of how they work, and this is probably more true of spectroscopic instruments than of any others, because of the frequent individuality of the problems to which they are applied.

K. J. HABell

\section{Computers and People}

Computers and Crisis: How Computers are Shaping Our Future. Edited by R. W. Bemer. Pp. 401. (Association for Computing Machinery: New York, 1971.)

UNLIKE the usual proceedings of technical conferences, this is a condensed report, which summarizes the principal points raised by the numerous contributors in the 115 sessions of the Conference of the Association for Computing Machinery in 1970.

The report was prepared in such a manner that ... "the result would be a readable volume for the generalist, requiring a minimum level of knowledge of, or contact with, the technical computer industry". To this end, Mr Bemer has to be congratulated for his efforts.

The conference sessions were categorized into seventeen sectors of interest. These sectors were further subdivided into special topics which were discussed in separate sessions. The entire list cannot be included here for obvious reasons. Some representative examples are: the sector on "Industry", which included sessions on "Food Dis- tribution", "Plant Automation", and "Printing and Publishing" amongst others; the sector on "Education", including "Computer Science Education" at the general, undergraduate and graduate levels; and finally, the sector on "Finance", including sessions on "Securities", "Insurance", "Banking" and "Accounting".

Although the topics cover a wide range of application areas, there were comments throughout the report on aspects of the computing environment which were of common concern. These were primarily on the use of computer networks and data banks. More specifically, the questions raised frequently concerned the reliability, privacy and security aspects of computer networks and data bases.

The observations, comments and opinions recorded were not only from the computer scientist or technologist, but also from people of different disciplines, whose common attribute was to have been near, or had access to, a computer. To stress the extent of the diversity, a selection of the participants is given here.

An FBI special agent commented on the effectiveness of the National Crime Information Center in law enforcement. A consultant, who is an ex-convict, described the plans for computer training courses for convicts as part of rehabilitation programmes. Finally, a representative from the US General Accounting Office discussed the introduction of computer technology into Congress, that is, into the processes of government. One interesting comment here was that Congressmen may have to write computer programs to assist them in their routine operations.

This volume should be read by all who are interested in how computers are shaping our future. Whether the predictions contained within will come true is a question for future historians, who will find this volume an invaluable source of information. A. L. LIM

\section{Liquid Crystals}

A Review of the Structure and Physical Properties of Liquid Crystals. By Glenn H. Brown, J. W. Doane and Vernon D. Neff. Pp. 95. (Butterworth: London, September 1971.) $£ 5$.

THIS review appeared in its present form as one of the CRC Critical Reviews in Solid State Sciences (Volume 1, Issue 3, September 1970). An appendix listing papers presented at the Third International Liquid Crystal Conference, Berlin, Germany, 1970, has, however, been added, together with some references on diffusion in liquid crystals. The review covers literature on liquid crystals mainly from 